\title{
Einführung \\ in die theoretische Physik
}

I n $\quad d r$ e i $B$ ä n d e n

Von

Dr. Clemens Schaefer

o. ö. Professor der Physik an der Universität Köln

\author{
D R ITTE R B A N D \\ ZWEITER TEIL \\ Quantentheorie \\ Mit 88 Figuren im 'Text
}

2. durchgesehene Auflage

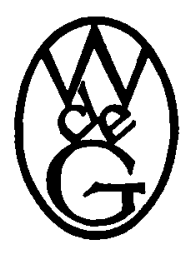

1951

WALTER DE GRUYTER \& CO.

vormals G. J. Göschen'sche Verlagshandlung - J. Guttentag, Verlagsbuchhandlung - Georg Reimer - Karl J. Trübner - Veit \& Comp.

Berlin W 35 
Alle Rechte, insbesondere das der Übersetzung, vorbehalten.

Copyright 1951 by Walter de Gruyter \& Co.

vormals G. J. Göschen'sche Verlagghandlung - J. Guttentag, Verlags. buchhandlung - Georg Reimer - Karl J. Trabner - Veit \& Comp.

Berlin W 35, Genthiner Strake 13 